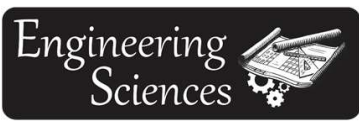

Journal homepage: www.sustenere.co/journals

\section{SENSORIAMENTO REMOTO NA PERÍCIA AMBIENTAL DO MINISTÉRIO PÚBLICO DO ESTADO DO PIAUÍ: ESTUDO DE CASO}

\section{RESUMO}

Este artigo descreve alguns dos usos da deteç̧ão remota em forenses ambientais no Ministério Público do Piauí. O estudo do meio ambiente tem muito a ganhar com o uso de dados remotos obtidos principalmente por sensores de satélite. Para fazer uma boa análise de análise, é necessária precisão e confiabilidade nas fontes. Além disso, em muitos casos, os dados devem ter data conhecida. O Ministério Público é a instituição governamental responsável pela defesa dos coletivos e sociais. Hoje em dia, o principal desafio da instituição é responder as necessidades sociais crescentes na sociedade. $\mathrm{O}$ objetivo principal deste documento de trabalho é demonstrar como seu dever foi melhorado pelo uso de informações georeferentes e imagens de satélites. Os exemplos de exames aqui apresentados demonstraram que o uso de ferramentas de geoprocessamento aliadas a dados de detecção remota tem sido usado com sucesso em forenses ambientais.

PALAVRAS-CHAVE: RapidEye; Legislação Ambiental Brasileira; Políticas Públicas; Crimes Ambientais; Desmatamento.

\section{REMOTE SENSING IN THE ENVIRONMENTAL EXPERTISE OF THE PUBLIC MINISTRY OF THE STATE OF PIAUÍ: CASE STUDY}

\section{ABSTRACT}

This paper describes some of the uses of remote sensing in environmental forensics in Public Ministry of Piauí. The study of the environment has a lot to earn with the use of remote data obtained primarily by satellite sensors. In order to make a good investigation analysis it is necessary accuracy and reliability on the sources. Also, in many cases, the data should have known date. The Public Ministry is the governmental institution responsible for defending the collectives and social wrights. Nowadays, the main challenge of the institution is respond the raising social needs in the society. The main goal of this work paper is demonstrate how its duty has been improved by the use of georefereces information and images from satellites. The examples of exams presented here showed that the use of geoprocessing tools allied to remote sensing data have been successfully used on environmental forensics.

KEYWORDS: RapidEye; Brazilian Environmental Law; Public Politics; Environmental Crimes; Deforestation.

\section{Engineering Sciences, Aquidabã,} v.2, n.1, Fev, Mar, Abr, Mai, Jun, Jul, Ago, Set, Out, Nov, Dez 2013, Jan, Fev, Mar, Abr, Mai, Jun, Jul, Ago, Set, Out, Nov 2014.

\section{ISSN 2318-3055}

\section{SECTION: Articles}

TOPIC: Engenharia Florestal

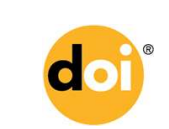

DOI: 10.6008/SPC2318-3055.2014.002.0002

Faruk Morais Aragão

Instituto Federal do Piauí, Brasil http://lattes.cnpq.br/9915754473992480 farukaragao@mppi.mp.br

Francisco de Assis da Silva Araújo Universidade Estadual do Maranhão, Brasil http://lattes.cnpq.br/4787682897870609 assisaa@gmail.com

Received: 21/03/2014

Approved: 12/09/2014

Reviewed anonymously in the process of blind peer. 


\section{INTRODUÇÃO}

O objetivo desse trabalho é mostrar como o Ministério Público do Estado do Piauí (MPPI) tem utilizado ferramentas de geoprocessamento, como informações georreferenciadas e imagens de satélites, para empoderar o seu processo de tomada de decisões em matéria ambiental.

Essas ferramentas e tecnologias foram utilizadas no MPPI em 2013-2014 para subsidiar a instauração de procedimentos administrativos, e inquéritos civis para prevenir danos ambientais e para apuração da responsabilidade dos agentes causadores de alterações dos recursos ambientais, em especial no tocante as seguintes operações de SIG: cálculo da área, cálculo de declividade, cálculo de distâncias, determinação de direções e análises topológicas.

O MPPI, enquanto órgão defensor dos interesses difusos, coletivos e sociais, vem aperfeiçoando a sua atuação junto à sociedade, tentando fazer frente à crescente demanda socioambiental do Estado.

A utilização de imagens disponíveis no Google Earth, apesar das reconhecidas limitações desse aplicativo era até pouco tempo a única forma de produção de prova em âmbito ministerial. A partir de junho de 2014 foi firmado termo de compromisso entre a Procuradoria Geral de Justiça e o Ministério do Meio Ambiente para o uso corporativo das imagens RapidEye através do aplicativo web Geo Catálogo do Ministério do Meio Ambiente.

Entre as estratégias que deveram ser priorizadas para o aprimoramento institucional, destaca-se o planejamento interno, voltado para gestão da informação, e por constituir-se numa ferramenta indispensável para o processo de gestão pública.

A atuação do Ministério Público, na área ambiental, necessita fundamentalmente de informações geradas pelos órgãos executores da política ambiental acerca de suas ações não somente do licenciamento e da fiscalização, mas também emerge a necessidade de acompanhamento do monitoramento ambiental, instrumentalizando a tomada de decisão dos órgãos ministeriais envolvidos na área ambiental.

\section{REVISÃO TEÓRICA}

\section{Perícias Ambientais com a Utilização de Técnicas de Geoprocessamento}

Segundo Florenzano (2008), o Sensoriamento Remoto é a tecnologia de aquisição, à distância, de dados da superfície terrestre, isto é, por meio de sensores instalados em plataformas terrestres, aéreas ou orbitais (satélites).

Este conceito evidencia a utilidade dessa tecnologia para a perícia ambiental, tendo em vista a obtenção de informações a respeito do objeto de estudo sem o contato direto, algumas vezes eliminando até mesmo a necessidade de exames de local. As ferramentas de sensoriamento remoto são ainda úteis no reconhecimento e no estudo prévio do local de exame, no planejamento do trabalho a ser executado e até mesmo na conclusão de alguns exames em particular (ALVES et al., 2012). 
Segundo Alves et al. (2012), as ciências forenses, por considerarem em suas análises o contexto do ambiente e a localização de um fato investigado, beneficiam-se do geoprocessamento na busca da verdade e da eficiência da produção da prova material.

O geoprocessamento pode também ser utilizado como ferramenta de planejamento e gestão ao espacializar a informação de interesse de qualquer Ministério Público, seja do Ministério Público da União (MPU) ou dos Ministérios Públicos Estaduais.

Com o auxílio de tecnologias de sensoriamento remoto, de sistemas de informações geográficas (SIG) e posicionamento via GNSS (GPS), largo espectro de perícias pode ser realizado, diminuindo a duração dos exames de local e ampliando a compreensão de fenômenos associados, em especial, aos crimes ambientais (ALVES et al., 2012).

As perícias de crimes relacionados a obras de engenharia podem servir-se do geoprocessamento para medições de estradas, barragens e reservatórios, avaliações de empreendimentos agropecuários, implantações de indústrias, entre outras. Os exames de local que exigem descrição detalhada dos componentes da cena do crime podem ser auxiliados pelas imagens com alta resolução espacial (ALVES et al., 2012).

A possibilidade de avaliação de uma mesma área em diferentes épocas, através de imagens multitemporais, auxilia a perícia na apresentação da dinâmica dos fatos e ainda possibilita exames indiretos em locais onde se verifica longo decurso de tempo entre 0 fato investigado e os exames periciais. Pode-se, por meio da utilização adequada de dados de geoprocessamento, caracterizar e quantificar a degradação ambiental decorrente de desmatamento, incêndios florestais, extração mineral, enchentes, determinados tipos de poluição, ocupação de áreas protegidas, bem como avaliar o efeito do dano ambiental sobre áreas limítrofes (ALVES et al., 2012).

A possibilidade de se obter uma visão panorâmica da região estudada, interessante para fenômenos que atinjam grandes áreas, como feições geológicas, greides de estradas, queimadas e desmatamentos, é de grande importância, pois concede ao perito e ou assistente técnico uma visão que este não teria apenas com a análise in loco da área. De outro lado, é possível obter informações detalhadas sobre um local, dependendo do tipo de produto de sensoriamento remoto (ALVES et al., 2012).

A utilização de banco de dados, contendo acervo histórico de imagens, auxilia a compreensão da dinâmica temporal da utilização da área de estudo, características de grande interesse em matéria ambiental.

Um dos maiores problemas encontrados há pouco tempo na área de perícias ambientais no MPPI era na observação das áreas de aplicação da Lei $n^{0} 11.428$ de 2006, que dispõe sobre a utilização e proteção da vegetação nativa do Bioma Mata Atlântica, e dá outras providências. Muitos são as solicitações do Centro de Apoio Operacional de Meio Ambiente do Ministério Público, e de promotorias do interior do Estado com o intuito de verificação por parte da perícia 
ministerial se empreendimentos se encontravam em áreas do Mapa da Área de Aplicação da Lei no 11.428 de 2006, mais conhecida como a Lei de proteção da Mata Atlântica.

Segundo Lang e Blaschke (2009) nos últimos anos, ao lado de uma pesquisa intensa sobre os comportamentos de índices e de sua relevância ecológica, foram produzidos diversos pacotes de aplicativos computacionais que disponibilizam, de formas diferentes, métricas descritoras de estruturas. Esses programas caracterizam a fragmentação de uma paisagem, fornecendo valores quantitativos de extensão de área e de distribuição espacial dos diferentes tipos de fragmentos que compõem uma paisagem (HESSBRURG et al., 2000).

A utilização de imagens disponíveis no Google Earth, apesar das reconhecidas limitações desse aplicativo era até pouco tempo a única forma de produção de prova pelo Ministério Público do Estado do Piauí. Atualmente na perícia ministerial do MPPI, estão sendo utilizadas duas ferramentas relacionadas à área de geotecnologia. Uma delas é o software Quantum GIS (QGIS), um sistema de informação geográfica (SIG) gratuito e licenciado sob a General Public License (GNU), portanto se trata de um software livre. Outra ferramenta é o aplicativo web Geo Catálogo do Projeto MMA onde em junho de 2014, foi firmado termo de compromisso entre a Procuradoria Geral de Justiça do Estado do Piauí e o Ministério do Meio Ambiente para o uso corporativo das imagens RapidEye. Esse termo se remete ao contrato de licença do usuário final (EULA).

RapidEye é uma constelação de 5 micro-satélites que foi lançada no dia 29 de agosto de 2008. É controlada pela empresa RapidEye AG, localizada em Brandenburg an der Havel, no estado de Brandenburgo, perto de Berlim, na Alemanha. A RapidEye AG é uma empresa de dados e serviços geoespaciais baseados em imagens de satélite para serem usados nas seguintes áreas: Agricultura, Floresta, Seguro, Óleo \& Gás, Governos, Cartografia, Visualização e Simulação.

As imagens RapidEye apresentam cinco bandas espectrais, que cobrem uma grande faixa do espectro. Além disso, dispõe da banda Red Edge, localizada entre o vermelho e o infravermelho próximo, e especialmente incluída para auxiliar na discriminação da vegetação e de corpos aquáticos (Santiago \& Cintra).

Os satélites têm uma resolução espacial de 5 metros e esta constelação de satélites é capaz de imagear mais de quatro milhões de quilômetros quadrados da superfície da Terra diariamente, resultando na possibilidade de imagear todo o estado de São Paulo em 06 dias com uma resolução de 5 metros.

O acesso do MPPI à cobertura de imagens RapidEye apenas do estado do Piauí pode ser realizado através deste aplicativo web que apresenta todas as informações necessárias incluindo seus metadados para que as mesmas possam ser adequadamente utilizadas pelos diferentes usuários em suas aplicações.

O Geo Catálogo do Projeto Ministério do Meio Ambiente, que está sendo acessado diariamente por centenas de usuários dos órgãos públicos, promove o compartilhamento das imagens e de todas as suas informações técnicas através da publicação de seus metadados em 
padrões ISO/OGC, recomendados pela Inde, assegurando a transparência tanto para os gestores quanto para os proprietários rurais que almejam conhecer as informações, métodos e regras a serem utilizados pelos gestores públicos.

O Aplicativo Web de entrega, organização, visualização, disseminação e compartilhamento das imagens RapidEye é uma solução inovadora com capacidade de catalogar grandes quantidades de dados, que permite maior transparência e potencial de compartilhamento entre os parceiros do Ministério do Meio Ambiente, para a obtenção de diagnósticos e das informações técnicas que deem suporte a tomada de decisões implementação de estratégias e políticas para promover a gestão ambiental e o uso sustentável dos recursos naturais em nível nacional (MMA, 2012).

O aplicativo web utilizado pela Santiago \& Cintra Consultoria para entrega das imagens, permite a pesquisa e disponibilização das imagens através de consultas por Municípios, Estados, Cenas, Coordenadas ou Polígonos geográficos e mostra as imagens disponíveis com seus respectivos metadados. Além disso, o aplicativo está aderente aos padrões ISO/OGC, baseado na tecnologia ERDAS Apollo, permitindo o acesso de serviços de WMS, WFS, WCS, WMTS e KML de servidores externos, inclusive com autenticação remota. Possuindo ainda um modelo de segurança para atribuir permissões de acesso, visualização ou download por usuário e/ou por área geográfica (MMA, 2012).

A segurança dos dados catalogados é protegida através de login e senha, criados para cada usuário do catálogo. Cada usuário pode ter acesso restrito às imagens, como por exemplo, acesso apenas às imagens RapidEye ou apenas a vetores (MMA, 2012).

O georreferenciamento realizado a partir de imagens obtidas com sensoriamento remoto é uma exigência do novo Código Florestal brasileiro (Lei $n^{\circ} 12.651$ de 2012) e serve como base para a elaboração do Cadastro Ambiental Rural (CAR). De acordo com o contrato assinado pelo MMA e a Santiago \& Cintra Consultoria, imagens dos satélites RapidEye serão o principal recurso do Ministério para chegar ao amplo conhecimento da cobertura das terras no Brasil. Com as imagens de alta resolução será possível identificar as áreas de aplicação da Lei $n^{\circ} 11.428$ de 2006, áreas de preservação permanente e reserva legal em cada propriedade e acompanhar a recuperação da cobertura vegetal onde a Lei exigir.

A utilização de SIGs em atividades relacionadas a crimes ambientais facilita o planejamento de exames de locais, a organização geográfica de informações colhidas em campo, à utilização de imagens de sensoriamento remoto para análise de fenômenos naturais ou antrópicos e a apresentação de pareceres periciais.

Dentre os recursos necessários para a implantação de SIG para atividades de criminalística podem ser citados: a obtenção de bases de dados cartográficos digitais, disponíveis em instituições de planejamento territorial ou órgão cartográfico oficial; a adoção de geoposicionamento de locais de interesse, o que pode ser realizado mediante o uso de receptores GNSS; a formação de bancos de dados multitemporais de sensoriamento remoto (fotografias 
aéreas, imagens óticas ou radar de sensores orbitais ou aerotransportados) das regiões de atuação da criminalística. Todas essas informações devem ser agrupadas e organizadas em um ambiental computacional designado como Sistema de Informação Geográficas, que pode ser gerenciado por diversos softwares comercias ou livres (ALVES et al., 2012).

A adequada estruturação de um SIG depende da confiabilidade e precisão dos dados utilizados, no aspecto do georreferenciamento de imagens, compatibilidade de projeções cartográficas e escalas, além dos aspectos computacionais de acessibilidade e velocidade de sistemas gerenciadores de banco de dados (ALVES et al., 2012).

Por exemplo, verificar, se desmatamento, está contido dentro de área da Mata Atlântica, a qual restringe seu uso tendo como base o Mapa da Área da Aplicação da Lei nº 11.428, de 2006. A utilização dos novos limites para os biomas brasileiros implicou na mudança da área total, da área de cada Estado, do total de municípios e da porcentagem de Mata Atlântica e de remanescentes em cada uma destas localidades. Tendo como banco de dados confiável para serem utilizados em perícias o repositório da SOS Mata Atlântica disponível em <http://www.sosmatatlantica.org.br/index.php>, úteis em análises topológicas.

Miranda et al. (2002), Santos et al. (2007), Cota e Moura (2009) e Moraes (2009) descreveram que a utilização de produtos de sensoriamento remoto e de técnicas de geoprocessamento podem contribuir na determinação automática das áreas de preservação permanente, desde que o banco de dados utilizado seja coerente e os modelos de interpolados adequados para esse fim.

\section{RESULTADOS E DISCUSSÃO}

O emprego de Sistema de Informação Geográfica (SIG ou GIS - Geographic Information System) na Coordenadoria de Perícias do Ministério Público do Piauí em matéria ambiental apresenta diversas aplicações as principais estão resumidas na Tabela 1.

Tabela 1: Principais operações requisitadas nas atividades periciais do Ministério Público.

\begin{tabular}{|c|c|}
\hline OPERAÇÃO & DESCRIÇÃO \\
\hline $\begin{array}{l}\text { Cálculo de } \\
\text { Distâncias } \\
\text { (CASO 1) }\end{array}$ & $\begin{array}{l}\text { Utilizada para se determinar a distância entre elementos do mapa como, por exemplo, distâncias viárias, ponto a } \\
\text { ponto, planejamento operacional de pericias. }\end{array}$ \\
\hline $\begin{array}{l}\text { Análises } \\
\text { Temporais } \\
(\text { CASO } 1+2)\end{array}$ & Acompanhar mudanças ocorridas em determinadas áreas durante específicos períodos de tempo. \\
\hline $\begin{array}{l}\text { Análises } \\
\text { Topológicas } \\
\text { (CASO 2) }\end{array}$ & $\begin{array}{l}\text { Estuda os objetos pelas relações entre si, tais como proximidade, conectividade, inclusão, coincidência, atributos. } \\
\text { Por exemplo, verificar se um ponto, dentro de uma determinada área, está contido em unidade de conservação, se } \\
\text { as árvores de um desmatamento estão sendo retiradas de uma área protegidas por lei. }\end{array}$ \\
\hline $\begin{array}{l}\text { Cálculo da área } \\
\text { (CASO 2) }\end{array}$ & $\begin{array}{l}\text { Utilizada para se determinar o tamanho de uma área, normalmente em } \mathrm{km}^{2} \text {, utilizado para se determinar as } \\
\text { dimensões entre as áreas das propriedades e áreas de preservação permanente (APP), planos de manejo florestal, } \\
\text { glebas, queimadas, desmatamentos. }\end{array}$ \\
\hline $\begin{array}{l}\text { Cálculo de } \\
\text { Declividade }\end{array}$ & $\begin{array}{l}\text { Utilizada para se determinar a declividade de um terreno. Utilizada em pericias na delimitação de APP, onde, acima } \\
\text { de } 45^{\circ} \text { de declividade, a área é considerada automaticamente APP. }\end{array}$ \\
\hline $\begin{array}{l}\text { Determinar } \\
\text { Direções }\end{array}$ & $\begin{array}{l}\text { Utilizada para se determinar fluxos de matéria como direções de ventos, direções fluviais, direções pluviais. } \\
\text { Utilizada normalmente em perícias de incêndios florestais, plumas de contaminação ambiental em rios ou até } \\
\text { mesmo em direção do fluxo das águas das chuvas. }\end{array}$ \\
\hline
\end{tabular}


Algumas das operações contidas na tabela 1 serão detalhadas através de casos práticos no tópico 2.2 e 2.3 a seguir.

\section{Caso 01: - Determinação da época de ocorrência de intervenção em Área de Preservação Permanente - APP: Utilização do Google Earth.}

Esta análise foi realizada em área localizada na zona leste do município de Teresina com a finalidade de constatar se em determinado local houve edificação em APP e a época de sua ocorrência, especificamente em qual mês do ano de 2013. A vistoria de campo realizada em 2014 constatou a intervenção, mas não permitiu determinar em que período esta aconteceu.

Os exames de local que exigem descrição detalhada dos componentes da cena do crime podem ser auxiliados pelas imagens com alta resolução espacial (Alves et al., 2012).

Assim, com a finalidade de conhecer a ação antrópica diferentes datas em imagens do Google Earth do local periciado que é uma imagem fusionada dos sensores pancromático e multiespectral acoplados no satélite QUICKBIRD 2, datadas de 23 de fevereiro de 2013 e 25 de setembro de 2013, fornecidas pela empresa DigitalGlobe, visualizada no banco de dados do Google Earth em 09/04/2014.

Vale salientar que as imagens contidas no banco de dados do Google Earth podem ser alteradas sem notificação. Portanto, as imagens descritas abaixo são duas imagens que estava no Google Earth na época do estudo, sendo que a mesma pode ser substituída por uma ou mais imagens a qualquer momento.

O trabalho foi executado apenas com imagens de possível utilização para o caso, mas esse tipo de situação pode ser diferente em outra área de estudo, pois dependendo da área pretendida pode existir mais de uma imagem contemplando a região. Nesse caso, as imagens devem ser tratadas separadamente em virtude da possibilidade de existirem registros diferentes e de serem de épocas distintas. No entanto as imagens da área em estudo além de possuírem alta resolução espacial são contempladas por uma única imagem. Não restringindo assim as aplicações.

A partir destas imagens foi possível observar que em fevereiro de 2013 a região encontrava-se, em sua maior parte, sem cobertura vegetação de tipologia florestal, com exceção de algumas árvores de porte elevado no canto inferior direito. Tais dados concordam com aqueles observados em perícia no local.

Já em setembro de 2013, figura 02 é possível observar intervenção na área de APP, inclusive com edificação e a ação erosiva das áreas marginas em decorrência de enxurradas.

Assim, a comparação entre as imagens Google Earth datadas de 23/02/2013 e de 25/09/2013 evidenciou variação significativa na ocupação da APP, tendo assim sido constatado que a ação antrópica, ou pelo menos, seu maior percentual, ocorreu após setembro de 2013. Após denúncia foi realizado algum tipo de recuo da edificação a qual com o crescimento da 
vegetação após o período das chuvas mascarou os indícios de edificação o que deixou a perícia em dúvida no dia 09/04/2014, sendo apenas constatado através da ferramenta chamada imagens históricas que possibilita fazer análise temporal e acompanhar mudanças ocorridas em determinadas áreas durante específicos períodos de tempo. Com isso, foi possível verificar que o assoreamento gerado pela degradação na bacia afetou diretamente o curso do rio e que realmente o empreendedor tinha cometido invasão através de edificação na APP.

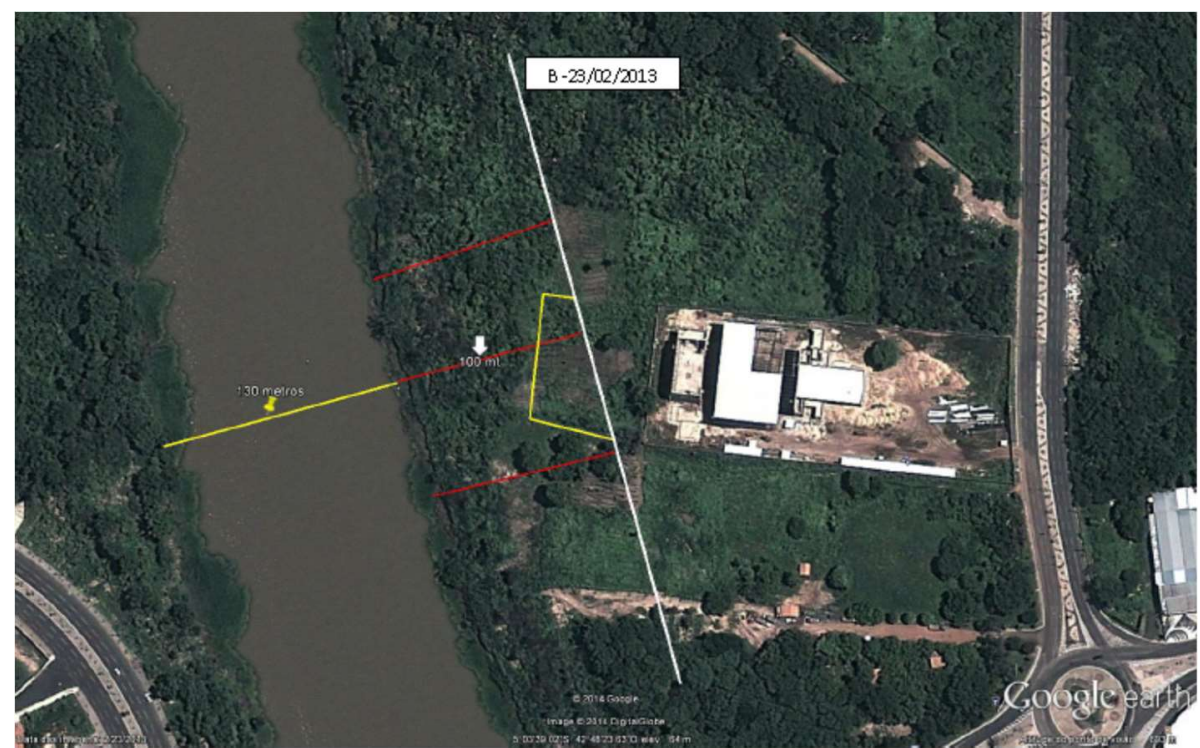

Figura 1: Área analisada em 23/02/2013, localizada através do Google Earth.

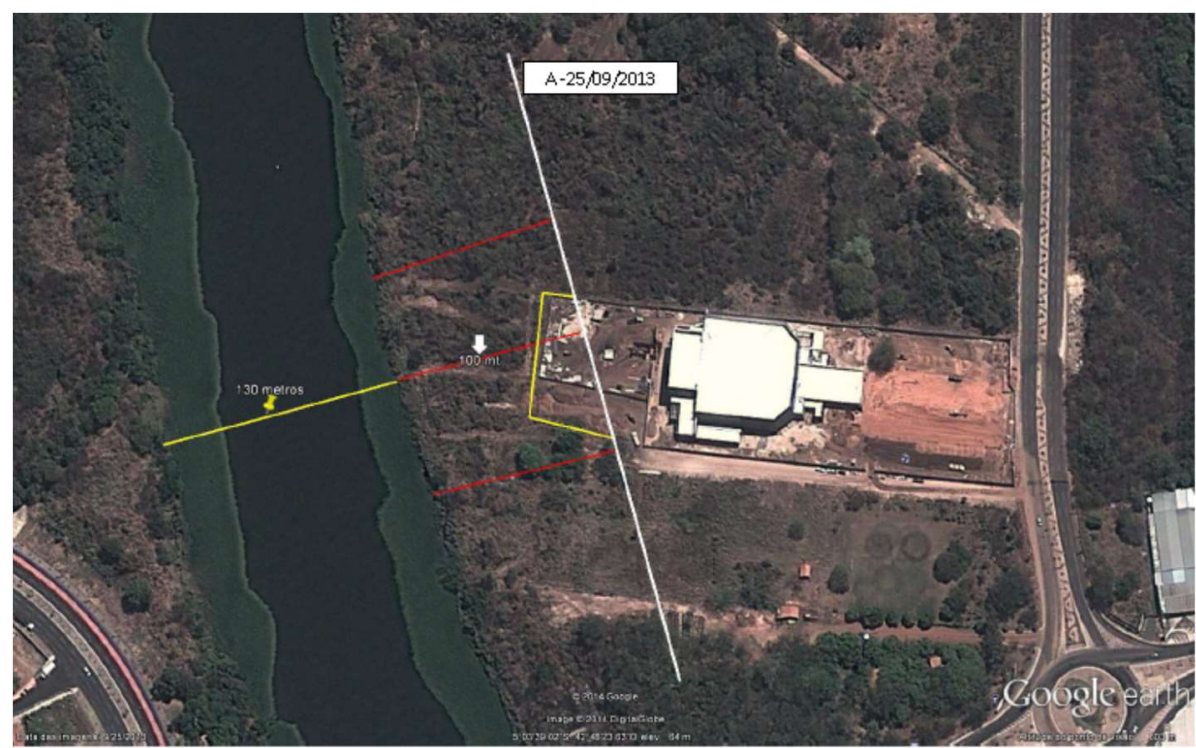

Figura 2: Área analisada em 25/09/2013, localizada através do Google Earth.

Caso 02: Desmatamento em áreas de aplicação da Lei $n^{\circ} 11.428$ de 2006: Uso do Quantum GIS e imagens RapidEye adquiridas pelo Geo Catálogo do MMA.

Está análise foi realizada na região centro-sul do estado do Piauí com a finalidade de constar se em determinado local houve supressão vegetal em área de aplicação da Lei $n^{0} 11.428$ de 2006 e se houve paralisação da supressão determinando a época de sua ocorrência, 
especificamente se foi após 2012. A vistoria de campo realizada em 2013 constatou o desmatamento, mas não permitiu determinar em que período este aconteceu.

Primeiramente, foram baixados do site do IBGE, em formato shapefile, os municípios do estado do Piauí. Logo em seguida foram baixados do site do SOS Mata Atlântica, também em formato shapefile das áreas de aplicação da Lei no 11.428 de 2006 no estado do Piauí.

Logo após, esses dados foram inseridos em ambiente SIG na plataforma do QGIS versão 2.4 (Chugiak). Ainda no QGIS foram delimitadas as áreas de ocorrência das florestas estacional decidual e semidecidual por município, separadas por ano de ocorrência, através das sobreposições alternadas das imagens RapidEye disponíveis no Geo Catálogo dos anos de 2011, 2012 e 2013. As imagens do ano de 2011 foram usadas como base, entendendo que o desmatamento teve início a parti deste ano, foi observado que no ano de 2012 existiu um desmatamento característico de Plano de Manejo.

No ano de 2013 não houve a ocorrência de novos desmatamentos na mesma área, isso se deve ao embargo ocorrido pelo IBAMA-PI. Ainda no ambiente SIG foi observado que a área se encontra dentro da área de aplicação da Lei nº 11.428 de 2006 (Figura 4).
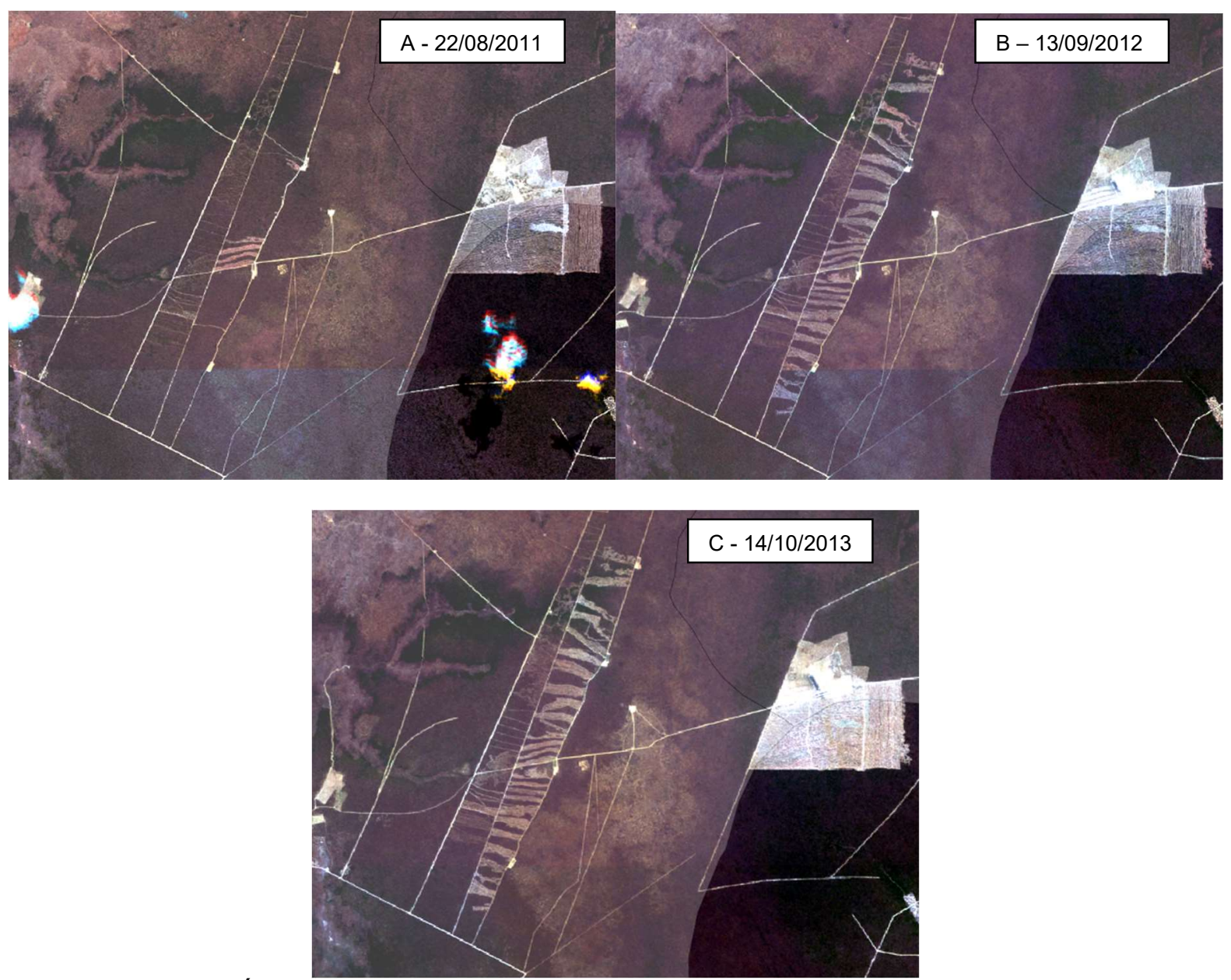

Figura 3. Área analisada em: A; B e C imagens ${ }^{\circledR} 2011,2012$ e 2013 RapidEye AG.

A área periciada se encontra entre duas imagens, assim foram utilizadas seis (06) imagens RapidEye, as duas primeiras de 22/08/2011 (Figura 1 -A); duas segundas de 13/09/2012 (Figura $1-B)$ e as duas terceiras de 14/10/2013 (Figura $1-$ C). 
A partir destas imagens foi possível observar que em 2011 a região encontrava-se, coberta com floresta estacional semidecidual. Tais dados concordam com aqueles do Atlas dos Remanescentes Florestais Da Mata Atlântica 2011-2012 (INPE, 2013).

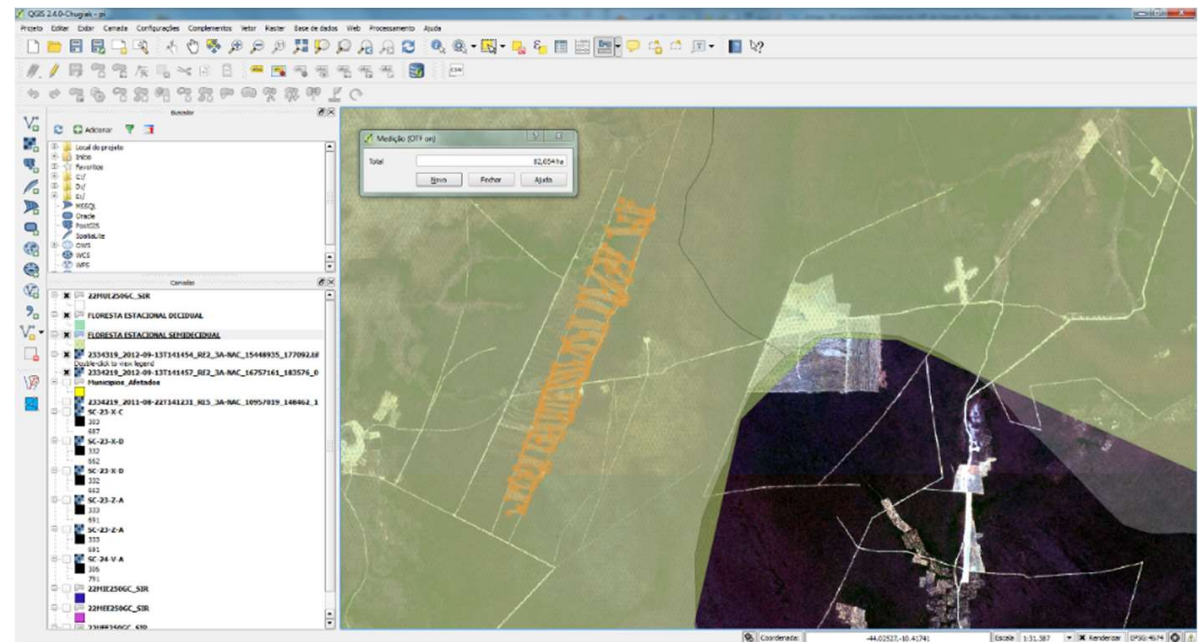

Figura 4: Produtos fornecidos ao Ministério Público do Estado do Piauí das áreas de aplicação da Lei $n^{\circ}$ 11.428 de 2006 com supressão vegetal destinada a carvoejamento. Área analisada em $\odot 2012$ RapidEye AG. Medição (OTF on) Total: 82,054ha. Município de Julio Borges (PMFS).

As imagens RapidEye do Geo Catálogo foram acessadas através do Quantum GIS, sem a necessidade de fazer download das imagens e nem as processas. Para acessar uma imagem no Quantum GIS através de WMS, é necessário primeiramente saber qual é a URL do WMS da imagem. Para isso, basta estar autenticado no Geo Catálogo e fazer uma busca normal por imagens.

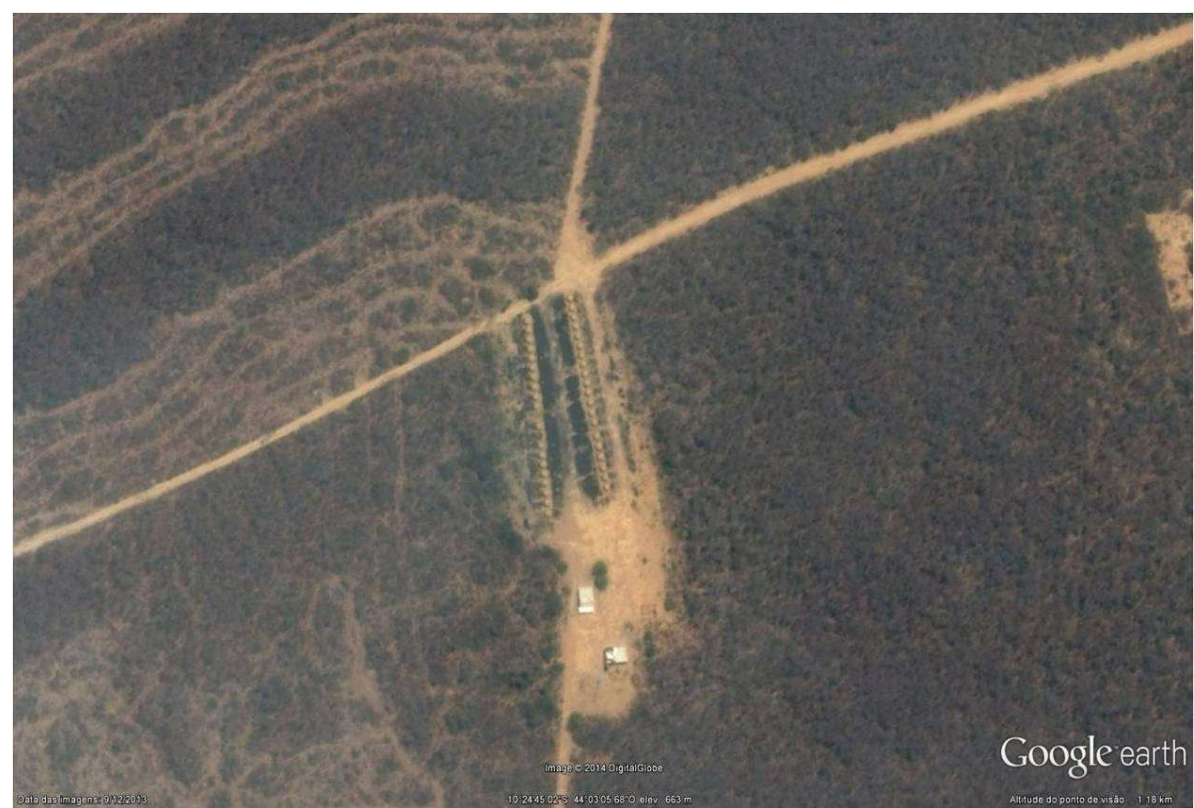

Figura 5: Uma das quatro baterias existentes na área portando 40 fornos, no ano de 2013, localizada através do Google Earth (2014).

Ao encontrar a imagem desejada, copia-se a URL do WMS, clicando com o botão direito sobre o link. Depois se abre o Quantum GIS acessa o menu Camada (adicionar camada WMS). Na janela do QGIS “Adicionar camada(s) de um servidor”, clica no botão Novo. Na próxima janela, 
insere um Nome, e colar URL do WMS copiada do Geo Catálogo MMA. Preencher o Usuário e Senha usados no Geo Catálogo MMA, e clica em OK. Voltando para a janela de adição de camada WMS, clica em Conectar e depois seleciona a camada desejada. Para finalizar, clica em Adicionar e depois em Close. Pronto agora, a imagem já pode ser acessada via WMS no Quantum GIS. Podendo-se trabalhar com os shapefiles e demais informações.

Utilizando o software Google Earth, com uma imagem do ano de 2013, foi confirmada a suspeita da existência de baterias de fornos, mostrando carvoaria, conforme Figura 5.

\section{CONCLUSÕES}

Os exemplos apresentados demonstram algumas aplicações do sensoriamento remoto (e do Google Earth) em âmbito pericial no Ministério Público Estadual. Tal tecnologia é de grande utilidade nos planejamentos prévios aos trabalhos de campo, permitindo que estes sejam realizados de maneira objetiva e eficiente.

O uso em conjunto do QGIS e das imagens RapidEye apresentou-se como uma solução para projetos relacionados à análise ambiental. Sendo possível através dos shapefiles das áreas protegidas a obtenção de informação que evidenciam a situação de degradação das áreas de aplicação da Lei no 11.428 de 2006, representando o descumprimento da legislação.

O acesso a imagens provenientes de sensores com diferentes resoluções espaciais e temporais permite que sejam feitas análises adequadas a cada caso, permitindo a verificação da existência ou não de materialidade no crime em tese cometido.

Demonstraram-se através de alguns exemplos, diversas aplicações desta tecnologia no que se refere aos esclarecimentos fáticos necessários para a adequada aplicação da legislação pertinente.

O empoderamento da instituição Ministério Público tornou mais célere a punição dos responsáveis por danos ambientais causados por uso indevido dos recursos naturais.

Os produtos de sensoriamento remoto são importantes ferramentas que vêm subsidiando o processo de tomada de decisões no Ministério Público do Estado do Piauí.

\section{REFERÊNCIAS}

ALVES, R. A. L.; RUSSO, D.; MAGLIANO, M. M.; BLUM, M. L. B.. Fundamentos de geoprocessamento aplicado a perícia. In: TOCCHETTO, D.. Perícia ambiental criminal. 2 ed. Campinas: Millennium Editora, 2012.

BRASIL. Manual de Uso do Aplicativo web de entrega, organização, visualização, disseminação e compartilhamento das imagens RapidEye. Geo Catálogo do Ministério do Meio Ambiente. Brasília: MMA, 2012.

COTA, M.A.; M., A. C. M.. Áreas de preservação permanente (APP): estudo de caso sobre o parâmetro declividade e as divergências nos resultados de mapeamento em função das bases cartográficas e escalas e/ou softwares utilizados. In: Seminário Brasileiro de Sensoriamento Remoto, 14, 2009, Natal. Anais... São José dos Campos: Instituto Nacional de Pesquisas Espaciais, 2009. 
FLORENZANO, T. G.. Sensoriamento Remoto para Geomorfologia. In: FLORENZANO, T. G.. Geomorfologia: conceitos e tecnologias atuais. São Paulo: Oficina de Textos, 2008.

FUNDAÇÃO SOS MATA ATLÂNTICA; INPE. Atlas dos remanescentes florestais da Mata Atlântica: relatório final. São Paulo: Fundação SOS, 2013.

LANG, S.; BLASCHKE, T.. Análise da paisagem com SIG. São Paulo: Oficina de Textos, 2009.

MORAES, R. P.. Geotecnologias na identificação de áreas de preservação permanente. Dissertação (Mestrado em Saneamento Ambiental e Recursos Hídricos) - Universidade Federal de Mato Grosso do Sul, Campo Grande, 2009.

MIRANDA, E. E.; GUIMARÃES, M.; MIRANDA, J. R.. Monitoramento do uso e cobertura das terras na região de Barrinhas, Jaboticabal e Sertãozinho. Campinas: Embrapa Monitoramento por Satélite, 2002.

MIRANDA, J. I.. Usando o Google Earth para publicar dados proprietários. Campinas: Embrapa Informática Agropecuária, 2005.

RAPIDEYE. Constellation Launch 2008. RapidEye AG, 2014.

SANTIAGO \& CINTRA CONSULTORIA. Sensoriamento Remoto: Conceitos, Tendências e Aplicações dos sistemas RapidEye. 2013. 